\title{
PEAK PRESSURES IN THE FOREFOOT
}

\author{
M. A. P. BRANSBY-ZACHARY, I. G. STOTHER, R. W. WILKINSON
}

From the Royal Infirmary, Glasgow and the Bioengineering Unit, Strathclyde University

\begin{abstract}
We used a high frequency response, ultra-thin transducer to measure forefoot pressures at predetermined sites on the sole of the foot in $\mathbf{1 0}$ normal subjects. We demonstrated impact pressure peaks, which have not previously been identified, and which were separate from the roll-off peak. We report preliminary results on the effect of various forms of footwear and insoles on sub-pedal pressure during walking.
\end{abstract}

Numerous methods are currently available to measure sub-pedal pressures; most recent publications assess the clinical use of the pedobarograph and force plate (Lord, Reynolds and Hughes 1986). Both these methods can record only a single footfall, and then only between the foot or shoe and the ground. Since most walking is done in shod feet, the methods have limitations.

To assess the effect of footwear and insoles on subpedal pressure direct measurement at the foot-insole interface is needed. Several authors have recognised this and a variety of transducers have been used in different circumstances (Lord 1981). Another advantage of direct measurement techniques with transducers is that several footfalls may be measured in sequence.

Transducers used in this way may be criticised on several counts. Their thickness may alter the normal gait of the subject (Shereff, Bregman and Kummer 1985; Ranu 1986); they have been embedded in rubber sheets to avoid discomfort (Lereim and Serck-Hanssen 1973; Frost and Cass 1981) but such an insole may itself affect the impact loads. Some devices may exhibit hysteresis and non-linearity, have poor response times, low sensitivity and be temperature or moisture dependent. Transducers with a low frequency response have been used in many studies; these may fail to demonstrate momentary pressure changes under the foot during walking. Devices based on a strain-gauged cantilever bar (Soames et al 1982) or a piezo-electric system (Hennig et al 1982) have the potential for recording high frequency responses.

We have analysed forefoot pressures using ultra-

M. A. P. Bransby-Zachary, FRCS Ed, Registrar

I. G. Stother, MA, FRCS Ed, FRCS G, Consultant

Department of Orthopaedic Surgery, the Royal Infirmary, 84 Castle Street, Glasgow G4 OSF, Scotland.

R. W. Wilkinson, BA, PhD, Lecturer

The Bioengineering Unit, Strathclyde University, Glasgow G4 OSF, Scotland.

Correspondence should be sent to Mr M. A. P. Bransby-Zachary

(C) 1990 British Editorial Society of Bone and Joint Surgery

$0301-620 X / 90 / 4118 \$ 2.00$

J Bone Joint Surg [Br] 1990; 72-B:718-21. thin, stainless steel pressure transducers placed under the first and third metatarsal heads.

\section{METHODS}

Ten healthy female volunteers with an average age of 25 years (range 20 to 42 ) were studied. None had any history of lower limb problems or any structural abnormalities on clinical examination.

Pressures beneath the first and third metatarsal heads were measured using a low profile $(0.9 \mathrm{~mm}), 35 \mathrm{bar}$, Entran transducer (Fig. 1). This is sealed and contains a

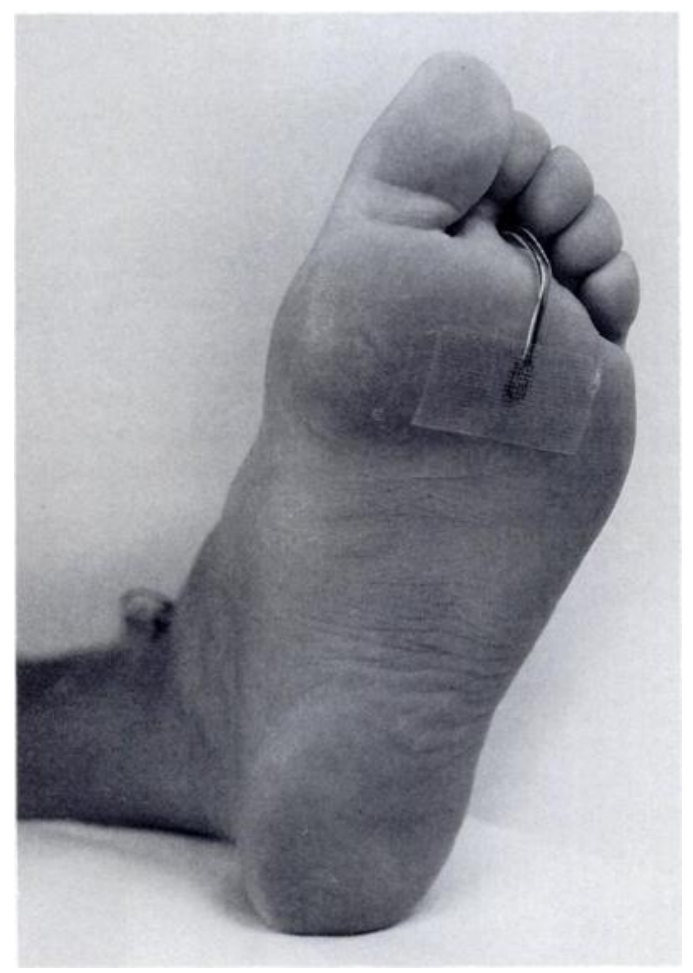

Fig. 1

Transducer in position over the third metatarsal head. 
silicon strain gauge with a metal diaphragm. It is temperature stable and has only $0.5 \%$ full-scale error for combined non-linearity and hysteresis. The transducer used had a diameter of $3.15 \mathrm{~mm}$ and a linear frequency response of $100 \mathrm{kHz}$. The peak height, the pressure-time integral (PTI), the step duration and step interval were all measured for each step. Calibration data was supplied by the manufacturer, and the overall system was rechecked using a calibration jig attached to a pedobarograph. The output was amplified and fed into the integral A-D converter of a BBC B + microcomputer.

The designated sites were palpated then marked. The first metatarsal head occasionally had a bony

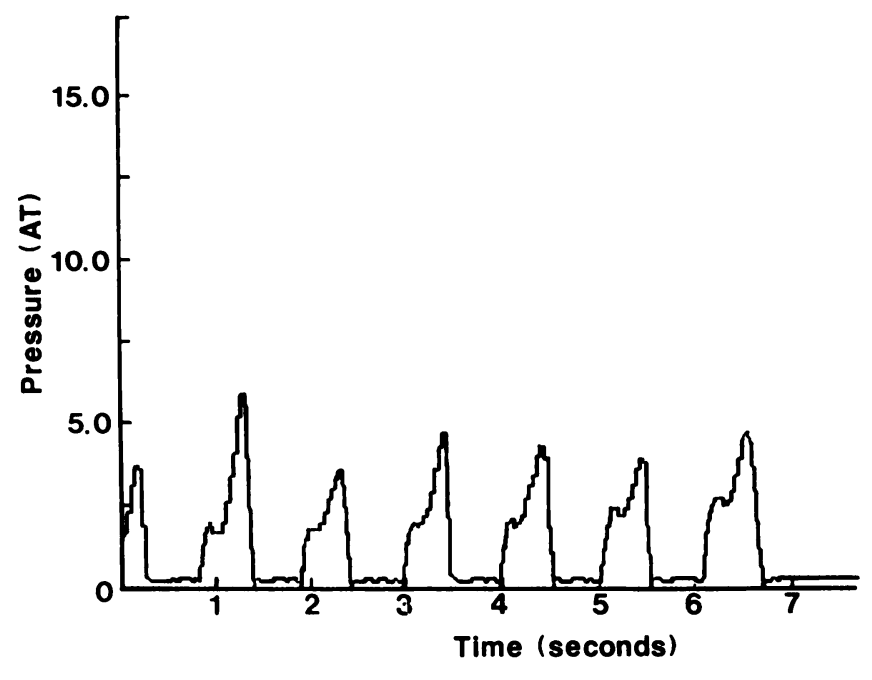

Fig. 2

Pressure profile under the third metatarsal head during barefoot walking. (AT), atmospheres.

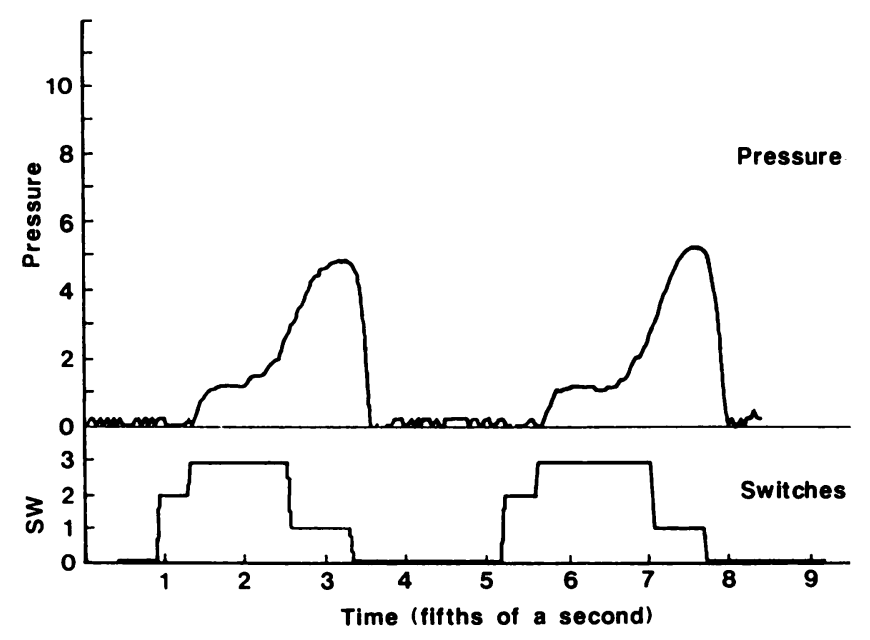

Fig. 3

Enlarged pressure profile for the third metatarsal head during barefoot related to the response of foot-switches. SW - 1 forefoot switch on; 2 heel switch on; 3 both switches on. prominence larger than the transducer diameter; in these cases the central point was selected. The transducer was attached by the least possible adhesive tape, the leads being brought round the foot and plugged into a connector taped at mid-tibial level. From this connector, a $3 \mathrm{~m}$ cable led to a trolley-mounted $\mathrm{BBC}$ microcomputer. Before testing, each subject walked for a time with the apparatus connected to allow her to become accustomed to the equipment. Alterations to the taping were made if needed to make the subject unaware of the transducer.

Each subject brought four pairs of her own shoes, one in each of the following categories: flat working, training shoes, medium $(3 \mathrm{~cm})$ heeled and high $(6 \mathrm{~cm})$ heeled shoes. Test walking was on a $14 \mathrm{~m}$ track over a wooden floor laid on concrete, at a comfortable constant speed. Recordings were made barefoot and with each category of footwear, both with and without a Protec 7 $\frac{1}{8}$ "-insole. Each test was repeated.

In one subject two switches were calibrated and barefoot testing repeated with the switches placed over the heel and medial forefoot. Measurements of the third metatarsal pressure were taken simultaneously with the switch responses. This data was sampled and analysed on a BBC microcomputer at a frequency of $100 \mathrm{~Hz}$.

\section{RESULTS}

Reproducible, double-peaked curves were obtained from both forefoot sites (Fig. 2) and were analysed in relation to the foot switch results (Fig. 3). This strongly suggested that the double peak consisted of an impact and a slightly later roll-off load.

\section{DISCUSSION}

We aimed to obtain a sensitive display of the pressure changes at the shoe-insole interface so that we could make accurate assessments of the effect of footwear and insoles. The transducer was particularly suitable because it had a high frequency response rate and, unlike other transducer based systems, avoided time dependency, hysteresis, temperature and moisture sensitivity and excessive size. A preliminary study showed that the metatarsal pattern of the bare foot was maintained in shoes, disagreeing with Soames et al (1982), who found that footwear increased the relative load under the first and second metatarsal heads. Sub-pedal pressure as a whole was reduced by the use of footwear, training shoes being the most effective.

The sensitivity of our system demonstrated a double peak, with high values at impact and at roll-off. We estimate that a frequency response of $50 \mathrm{~Hz}$ or more is required to demonstrate this satisfactorily. Asymmetry in the forefoot peaks was noted as early as 1947 by Schwartz and Heath using a 'piezometric' transducer and more recently Soames et al (1982) showed forefoot peaks with a definite shoulder. The significance of this finding 
was discussed by neither author; only a single symmetrical forefoot peak was found in studies which used transducers of a low frequency response (Shereff et al 1985).

The pressure-time integral (PTI) represents the change in momentum of the subject. Soames (1985) considered that this could be a better indicator of foot function than contact time and peak pressure separately. The PTI also gives information on the second smaller peak within the pressure-time curve for each footfall. Where the peak heights and peak duration remain little changed, comparison of these secondary peaks may be made.

The roll-off pressure is normally greater than the impact pressure and is thus represented by the peak pressure. Alterations in footwear, heel height, and the use of insoles have little effect on the peak pressures but all have a significant effect on the impact pressures. Training shoes reduce the impact pressure under the first metatarsal head by $60 \%$ and insoles cause a reduction of $17 \%$. Increasing the heel height increases impact pressures.

An increase in the PTI with heel height was noted by Soames et al (1982); they attributed it to prolonged forefoot contact time. Our study has not shown any significant increase in the forefoot contact time with increasing heel height; this strongly suggests that the increase in PTI was due to higher impact pressures. Direct measurement of the impact peak confirmed this.

Step to step variation was seen in each subject, particularly for the first two steps and the last one. Where this variation was marked, the peak for that step was excluded from the analysis, which therefore refers only to the middle period of walking after the initial acceleration and before terminal deceleration.

The typical double peak profile included a smaller impact load and a larger roll-off load, and elevation in the peak height was due to increased roll-off pressure. Where the peak height and peak time remained constant, any changes in the area under the curve (the pressuretime integral) represented alterations in the total impact load.

The average peak pressure under the first metatarsal at roll-off was $5.95 \mathrm{~kg} / \mathrm{cm}^{2}$ and under the third metatarsal was $5.88 \mathrm{~kg} / \mathrm{cm}^{2}$. The use of footwear reduced these pressures by an average of $32 \%$. Training shoes had the most significant effect, providing a $21 \%$ reduction compared with any other shoes. Impact pressures, as

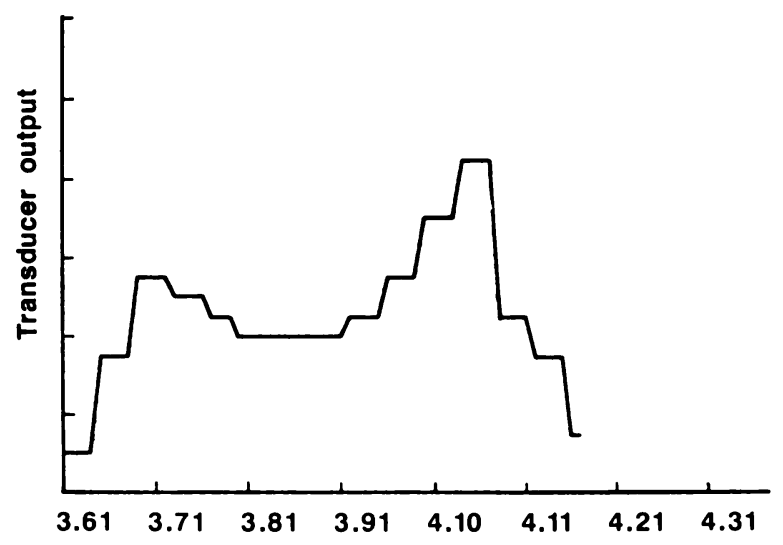

Fig. 4

Enlarged pressure profile for the third metatarsal head during walking in high heeled shoes.

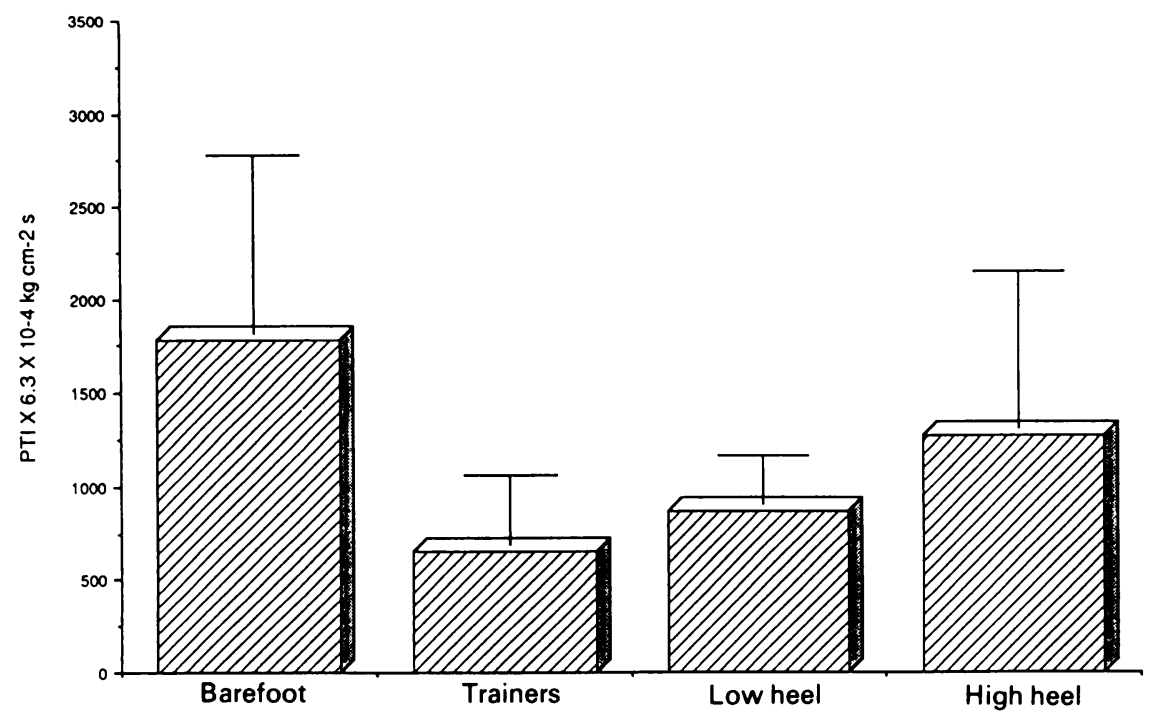

Fig. 5

The effect of heel height on the pressure-time integral (PTI) beneath the third metatarsal head, barefoot and in various footwear. 
estimated by changes in the pressure-time integral were also greatly reduced by the use of footwear $(46 \%)$ and again training shoes had the largest effect $(63 \%)$. The use of insoles had no effect on the roll-off pressure but provided a $17 \%$ reduction in the impact pressure.

There was no significant variation in the forefoot contact times in relation to heel height, but the use of a higher heel caused increased impact pressures. The $3 \mathrm{~cm}$ heel caused an increase of $25 \%$ over the flat shoe and the $6 \mathrm{~cm}$ heel a $48 \%$ relative increases (Figs 4 and 5).

The limitations of our study were that only two areas of potential interest were studied, with no simultaneous recordings from other areas of the foot. Only a single transducer was available at the time, but we are now developing a multiple transducer system.
Conclusions. Forefoot pressures are consistently reduced by certain types of footwear and by the use of insoles. Heel height has little effect on the roll-off load but reduces the impact loads. To study the effect of footwear, measurement of the impact pressure peak is necessary, and this requires the use of a transducer system with a high frequency response.

We would like to thank the Greater Glasgow Health Board and the Royal College of Surgeons of Edinburgh for their sponsorship of this work and Mr A. J. Tullis of the Bioengineering Unit of Strathclyde University for the production of the amplifiers and his general assistance.

No benefits in any form have been received or will be received from a commercial party related directly or indirectly to the subject of this article.

\section{REFERENCES}

Frost RB, Cass CA. A load cell and sole assembly for dynamic pointwise vertical force measurement in walking. Eng Med 1981; 10:45-50.

Hennig EM, Cavanagh PR, Albert HT, Macmillan NH. A piezoelectric method of measuring the vertical contact stress beneath the human foot. J Biomed Eng 1982; 4:213-22.

Lereim P, Serck-Hanssen F. A new method of recording pressure distribution under the sole of the foot. Bulletin of Prosthetic Research 1973; Fall:118-25.

Lord M. Foot pressure measurement: a review of methodology. $J$ Biomed Eng 1981; 3:91-9.

Lord M, Reynolds DP, Hughes JR. Foot pressure measurement: a review of clinical findings. J Biomed Eng 1986; 8:283-94.
Ranu HS. Miniature load cells for the measurement of foot-ground reaction forces and centre of foot pressure during gait. $J$ Biomed Eng 1986; 8:175-7.

Schwartz RP, Heath AL. The definition of human locomotion on the basis of measurement. J Bone Joint Surg 1947; 29:203-14.

Sherefi MJ, Bregman AM, Kummer FJ. The effect of immobilization devices on the load distribution under the foot. Clin Orthop 1985; 192:260-7.

Sormes RW, Stott JR, Goodbody A, Blake CD, Brewerton DA. Measurement of pressure under the foot during function. Med Biol Eng Comput 1982; 20:489-95.

Soames RW. Foot pressure patterns during gait. J Biomed Eng 1985; $7: 120-6$. 